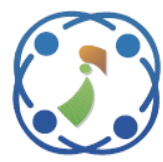

\title{
Emergency Load Shedding for Voltage Stability Enhancement: With Particular Reference to the Iraqi National Power Grid
}

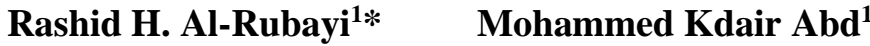 \\ Department of Electrical Engineering, University of Technology, Iraq \\ * Corresponding author’s Email: 30062@uotechnology.edu.iq
}

\begin{abstract}
In the present days, power systems are operated favourably close to their stability limit. System stability can be safeguarded by employing an emergency control technique, known as load shedding; this technique is affected by shedding some loads. Such a technique implemented only when the voltage or frequency deterioration below a specific voltage or frequency threshold. In this work, an advanced emergency load shedding model is forwarded based on the voltage stability indicator aimed at enhancing voltage. This indicator facilitates online monitoring of voltage stability and predicts the voltage problem of the system with sufficient accuracy, fast and simple numerical calculation, also can work well in the steady-state as well as during the transient process. The proposed model and algorithm have been tested firstly on the IEEE 14 bus system as a standard system and then implemented on the Iraqi National Power Grid (INPG) as a particular reference system. The obtained results for the voltage profile has recovered by $11.1 \%$ for the standard system and $2.03 \%$ for the particular system.
\end{abstract}

Keywords: Voltage stability, Emergency load shedding, Voltage stability indicator, Load shedding amount, Time steps of load shedding.

\section{Introduction}

Voltage stability is essential regards that require considerable attention in the planning and operation of the power system. It is proven that voltage instability can lead to significant system failure. A severe imbalance between load demands and power generation in the system can result when large sudden disturbances, such as faults, large load changes, inadvertent tripping of lines and generators occur. The results of which may be a rapid drop in voltage and a decline in frequency.

Instability of voltage results in a condition of substantial voltage drop for all buses of the system. Consequently, justification action is required. Once such lessening actions, to counteract voltage instability, is emergency load shedding, which performs a vital role in improving voltage stability. The approach of load shedding is a decisive counteracting contingency to avoid power system collapsing as a result of great disturbances.
Thus, the system may not respond rapidly enough to such disturbances. Voltage and frequency, as system variables, depart from the permissible limits; an instability condition occurs, the controllers of the system operate to restore the system to the normal state. Under very large disturbance condition, the operation of control and compensate-ion devices, such as automatic voltage regulators, turbine governors, and FACTS, will be ineffective to restore the voltage and frequency to their acceptable range. Under such condition, the load shedding strategy becomes highly urgent to be applied, which implies it the final solution to avoid power system breakdown [1].

The consequences of enormous disturbances are cascading faults. Due to this, the system will collapse, and this is caused by an imbalance in the load demand and power generation, which leads to instability of frequency and voltage [2]. However, the load shedding structures are Under Frequency Load Shedding (UFLS) and Under Voltage Load 
Shedding (UVLS), which have been designed separately, where they establish the final protection against frequency and voltage instabilities [3, 4]. The approach of load shedding based on the possibility of detaching some loads or a percentage of them, following a severe disturbance aimed at relocating the operating point far out from the critical voltage collapse value.

Wiszniewski [5] introduced a methodology for the load shedding strategy by giving new criteria of voltage stability margin. Girgis and Mathure [6] in this paper a methodology has been presented showing the rate of change in frequency that can be used to determine the amount of the imbalance between generation and demand, while the rate of change in voltage with respect to active power can be used to identify the most appropriate bus for load shedding. Fu and Wang [7] introduced an advanced algorithm to study the problem of emergency load shedding, where cannot be found power flow solution for the stressed system.

Arya and Singh [8] presented a methodology to optimize the load shedding necessary to restore the equilibrium of operating point. The buses with large sensitivity are selected for load curtailments. A computational algorithm was developed using Differential Evolution (DE) for minimum load shedding at selected load buses. The proposed approach (DE) has been applied on IEEE 14-bus and 25-bus test systems. Performance of the DE methodology has been compared with Particle Swarm Optimization (PSO), Co-ordinated Aggregation based Particle Swarm Optimization (CAPSO) and Genetic Algorithm (GA) techniques.

This article aims to determine the location and amount of load to be shaved at a weak load bus to avoid voltage instability, based on the voltage stability indicator. This indicator helps to online monitoring network operation, location and amount of load shedding prediction, rapid diagnosis and perfect decision making. A critical high system load level causes the voltage instability considered here.

Initially, the activity of the proposed model and algorithm were tested on IEEE 14 bus system as a standard system, after that implemented on the INPG as a particular reference system. This paper is organized as follows:

Section 2, describes the issues that should be taken into consideration when researching the load shedding technique, these issues are a suitable location of load shed, the quantity of load to be shed at the identified positions and the timing of load shed; The relationship between voltage stability indicator change and the change in load power to be shed is detailed in section 3; In section 4, the proposed algorithm is implemented for two systems, which are test system and INPG as a particular network; Finally, section 5 represents the conclusion of work.

\section{Load shedding strategy}

To ensure efficient load shedding procedures, three aims need to be considered $[9,10]$ :

\subsection{Determining the proper amount of load shedding}

A sufficient amount of load shedding is essential to guarantee UVLS can alleviate the hazard of voltage instability, and it is an economical solution to mitigate the collapse of a system where small load curtailment between (5 and 10) \% can preserve the system stability.

Shedding an inadequate amount of the demanded power from load buses will not be influential in the collapse of voltage; furthermore, curtailment of more demanded load than wanted may driving to the condition of an over frequency. The quantity of load shedding depends partly on the type of emergency, the effective load shedding policy, as well as the system configuration.

\subsection{Locating a suitable location for load shedding}

Shedding load in a specific location (load bus) can stop voltage instability. But, the same amount of load shedding in various load bus yields several results and may not be operative to enhance the system voltage stability [11]. There are several techniques that have been suggested in the literature for estimating and expecting voltage stability using steady-state analysis methods. Some of these techniques include $\mathrm{P}-\mathrm{V}$ curves, $\mathrm{Q}-\mathrm{V}$ curves, modal analysis, minimum singular value, sensitivity analysis, and reactive power optimization [12]. These methods are the static approach; however, for the dynamic process (voltage stability) these technique does not give sensitivity information useful, another restriction of these methods is that they focus on a few buses.

System power flow analysis is frequently a valuable tool for voltage stability analysis; this is affected by monitoring system voltages as a function of load change. Kessel [13] projected the L-index, which allocates a scalar number to each load bus. The range of index value is between $(0,1)$. If the index value is zero, it indicates that the bus is at noload condition, and the bus is thought to be on the threshold of voltage collapse if the index value is one. Bus possessing the highest value of L-index 
will be the biggest vulnerable bus in the power system. This method assists in recognizing the weak buses in a power system, which require a suitable action to take.

\subsection{Determining time steps of load shedding}

Shedding of the load is implemented in steps to avert over shedding state. The minimum time delay prior to UVLS to be triggered should be adequate in thwarting voltage instability in addition to avoiding needless tripping during a transient time where employment of load shedding is pointless.

A load shedding structure usually has several stages; each one is characterized by the frequencyvoltage threshold, quantity of load, and time delay prior tripping. An effective load shedding system aims to truncate a minimum amount of load and offer a fast, smooth, and safe shift of the power system from an emergency to a normal stable condition [14].

\section{Problem formulation}

The load shedding method should occur at a minimum number of load buses. Such buses must be selected, and then the amount of load shedding must be decided from operating and stability restrictions viewpoint.

Here has been developed the relationship between changes in the voltage stability indicator (L-index) and load powers designated to be shed. By means of this relation, the best location and amount of load power to be shaved is determined.

A) The relation between voltage stability indicator and state variables $(V, \delta)$ : In a power system, the bus current equation stated in matrix form is:

$$
I_{b u s}=Y_{b u s} V_{b u s}
$$

Consider a power system, where $n$ represents the number of buses and generator buses labelled as $1,2 \ldots g$, and the remaining are load buses labelled $g+1 \ldots . . n$.

The partitioned matrix form of Eq. (1) is given in Eq. (2):

$$
\left[\begin{array}{c}
I_{G} \\
I_{L}
\end{array}\right]=\left[\begin{array}{cc}
Y_{G G} & Y_{G L} \\
Y_{L G} & Y_{L L}
\end{array}\right]\left[\begin{array}{c}
V_{G} \\
V_{L}
\end{array}\right]
$$

Where $I_{G}, I_{L}$ and $V_{G}, V_{L}$ are the currents and voltages at the generator and load buses. Manipulating and arranging Eq. (2) yields Eq. (3):
$\left[\begin{array}{c}V_{L} \\ I_{G}\end{array}\right]=\left[\begin{array}{ll}Z_{L L} & F_{L G} \\ K_{G L} & T_{G G}\end{array}\right]\left[\begin{array}{c}I_{L} \\ V_{G}\end{array}\right]$

Where:

$Z_{L L}=\left[Y_{L L}\right]^{-1} ; F_{L G}=-\left[Y_{L L}\right]^{-1}\left[Y_{L G}\right] ; K_{G L}=\left[Y_{G L} Z_{L L}\right]$ and $T_{G G}=\left[Y_{G G}-Y_{G L} Z_{L L} Y_{L G}\right]$.

For a given system, if the generator bus is $i$ and the load bus is $j$, then $F_{L G}$ in Eq. (3) becomes:

$$
\begin{aligned}
F_{j i}= & -\left[Y_{j j}\right]^{-1}\left[Y_{j i}\right]=F_{j i} \angle \theta_{j i} \\
& =F_{j i}\left(\cos \theta_{j i}+j \sin \theta_{j i}\right)
\end{aligned}
$$

By using load flow results, acquired for given system loading conditions, the voltage stability indicator (L-index) at bus $j$ is computed using Eq. (5) $[13,15]$ :

$L_{j}=\left|1-\frac{i \propto \sum_{G} F_{j i} V_{i}}{V_{j}}\right|$

Where: $j=g+1 \ldots \ldots . n, F_{j i}$ is a complex quantity, $V_{i}$ and $V_{j}$ are the complex bus voltages at generator buses and load buses respectively.

Substituting for $F_{j i}$ from Eq. (4) into Eq. (5), results in:

$$
\begin{aligned}
L_{\mathrm{j}} & =\mid 1-\sum_{i=1}^{g}\left(F_{j i} \cos \left(\theta_{j i}+\delta_{i}-\delta_{j}\right)\right) \frac{V_{i}}{V_{j}} \\
& -j \sum_{i=1}^{g}\left(F_{j i} \sin \left(\theta_{j i}+\delta_{i}-\delta_{j}\right)\right) \frac{V_{i}}{V_{j}} \mid
\end{aligned}
$$

The L-index at bus $j$ is a function of the state variables (voltage angle and magnitudes) at the same bus. The real part and imaginary part of Lindex can be described as given in Eq. (7) and Eq. (8):

$$
\begin{aligned}
& f\left(V_{j}, \delta_{j}\right)=L_{j}^{R} \\
& =1-\sum_{i=1}^{g}\left(F_{j i} \cos \left(\theta_{j i}+\delta_{i}-\delta_{j}\right)\right) \frac{V_{i}}{V_{j}} \\
& g\left(V_{j}, \delta_{j}\right)=L_{j}^{I} \\
& =1-\sum_{i=1}^{g}\left(F_{j i} \sin \left(\theta_{j i}+\delta_{i}-\delta_{j}\right)\right) \frac{V_{i}}{V_{j}}
\end{aligned}
$$


The partial derivative of Eqs. (7) and (8) with respect to state variables variations can be determined as shown next:

$\left[\begin{array}{c}\Delta L_{j}^{I} \\ \Delta L_{j}^{R}\end{array}\right]=[M]\left[\begin{array}{l}\Delta \delta_{j} \\ \Delta V_{j}\end{array}\right]$

Where $[M]$ represents the matrix of sensitivity between L-index changes and state variables changes, and its elements can be written as in the following:

$$
\begin{aligned}
& {[M]=\left[\begin{array}{ll}
\frac{\partial L_{j}^{I}}{\partial \delta_{j}} & \frac{\partial L_{j}^{I}}{\partial V_{j}} \\
\frac{\partial L_{j}^{R}}{\partial \delta_{j}} & \frac{\partial L_{j}^{R}}{\partial V_{j}}
\end{array}\right]} \\
& =\left[\begin{array}{ll}
-\frac{F_{j i} V_{i} \cos \left(\theta_{j i}+\delta_{i}-\delta_{j}\right)}{V_{j}} & \frac{F_{j i} V_{i} \sin \left(\theta_{j i}+\delta_{i}-\delta_{j}\right)}{V_{j}^{2}} \\
\frac{F_{j i} V_{i} \sin \left(\theta_{j i}+\delta_{i}-\delta_{j}\right)}{V_{j}} & -\frac{F_{j i} V_{i} \cos \left(\theta_{j i}+\delta_{i}-\delta_{j}\right)}{V_{j}^{2}}
\end{array}\right]
\end{aligned}
$$

B) The relation between the load demand and state variables $(\boldsymbol{V}, \delta)$ : From the power flow Newton-Raphson algorithm a linear relationship between changes in the state variables and changes in the power injections [16], this relation for bus $j$ is expressed by the following:

$$
\left[\begin{array}{c}
\Delta \delta_{j} \\
\Delta V_{j}
\end{array}\right]=[J]^{-1}\left[\begin{array}{c}
\Delta P_{j} \\
\Delta Q_{j}
\end{array}\right]
$$

Where $[J]$ is a Jacobian matrix.

C) The relation between voltage stability indicator and load demand: By combining Eqs. (9) and (11), the direct relationship between change in the voltage stability indicator (L-index) at load bus $j$ and change in bus demand powers is obtained as:

$$
\left[\begin{array}{c}
\Delta L_{j}^{I} \\
\Delta L_{j}^{R}
\end{array}\right]=[M][J]^{-1}\left[\begin{array}{c}
\Delta P_{j} \\
\Delta Q_{j}
\end{array}\right]
$$

$$
\left[\begin{array}{c}
\Delta L_{j}^{I} \\
\Delta L_{j}^{R}
\end{array}\right]=[T]\left[\begin{array}{c}
\Delta P_{j} \\
\Delta Q_{j}
\end{array}\right]
$$

Where $[T]=[M][J]^{-1}$

$$
\begin{aligned}
& \Delta L_{j}^{I}=T_{11} \Delta P_{j}+T_{12} \Delta Q_{j} \\
& \Delta L_{j}^{R}=T_{21} \Delta P_{j}+T_{22} \Delta Q_{j}
\end{aligned}
$$

Commonly, a relation between real and imaginary power at load bus $j$ can be written as below:

$$
K_{j}=\frac{\Delta Q_{j}}{\Delta P_{j}}
$$

Where $K_{j}=\sqrt{\frac{1}{\left(P f_{j}\right)^{2}}-1}$, and $P f_{j}$ is the power factor of the load at bus $j$. Substituting Eq. (16) in Eq.(14) and Eq. (15), yields:

$$
\begin{aligned}
\Delta L_{j}^{I} & =T_{11} \Delta P_{j}+T_{12} K_{j} \Delta P_{j} \\
\Delta L_{j}^{R} & =T_{21} \Delta P_{j}+T_{22} K_{j} \Delta P_{j} \\
\Delta L_{j}^{I} & =Z_{1} \Delta P_{j} \\
\Delta L_{j}^{R} & =Z_{2} \Delta P_{j}
\end{aligned}
$$

Where:

$Z_{1}=T_{11}+T_{12} K_{j}$ and $Z_{2}=T_{21}+T_{22} K_{j}$

$$
\Delta L_{j}=\sqrt{\left(\Delta L_{j}^{I}\right)^{2}+\left(\Delta L_{j}^{R}\right)^{2}}
$$

Substituting Eq. (19) and Eq. (20) in Eq. (21), we obtained a relationship between change in the voltage stability indicator (L-index) at load bus $j$ and the change in active power introduced at the same load bus as:

$$
\Delta L_{j}=\Delta P_{j} \sqrt{\left(\mathrm{Z}_{1}\right)^{2}+\left(\mathrm{Z}_{2}\right)^{2}}
$$

\section{D) The voltage recovery concept:}

It is difficult to deal with many bus voltages to determine whether there is an improved voltage in 
the network, because voltage improvement may have occurred in some buses and not in others, or may have become worse in some buses. In this paper, a new index of the voltage recovery $\left(V_{\text {rec. }}\right)$ used for the management of all bus voltages. The index is illustrated in Eq. (23):

$V_{\text {rec. }} \%=\frac{\left(V_{a v}\right)_{A S}-\left(V_{a v}\right) B S}{\left(V_{a v}\right)_{B S}} \times 100$

Where $\left(V_{a v}\right)_{A S}$ is the average voltage after shedding and $\left(V_{a v}\right)_{B S}$ is the average voltage before shedding, and average voltage $\left(V_{a v}\right)$ is defined as:

$V_{a v}=\frac{\sum_{i=1}^{N_{n}} V_{i}}{N_{n}}$

Where $V_{i}$ is the voltages at bus $i ; N_{n}$ is the number of network buses.

The procedure for programming load shedding can be described as follows:

Step.1: Determine the amount of load shedding, the percentage of a load to be shed for each iteration is selected at $10 \%$.

Step.2: Select the type of disturbance.

Step.3: Implement power flow by NewtonRaphson Method.

Step.4: Compute the (L-index) for all load buses, and identify critical zones which have a similar pattern of voltage drop. The bus with the highest value of (L-index) represents a suitable location for load shedding and has the greatest impact to enhance the system voltage magnitude.
Step.5: Apply load shedding on the selected bus.

Step.6: Carry out power flow to evaluate the system performance after load shedding.

Step.7: If the system remains unstable, then data of the network is updated and go to Step (3). This procedure will be repeated till the voltage stability constraint is fulfilled.

Step.8: Calculate the voltage recovery.

Step.9: Print the results and stop the program.

\section{Results and discussion}

The impact of the proposed model and algorithm have been tested initially on IEEE 14 bus system, and then applied on the INPG.

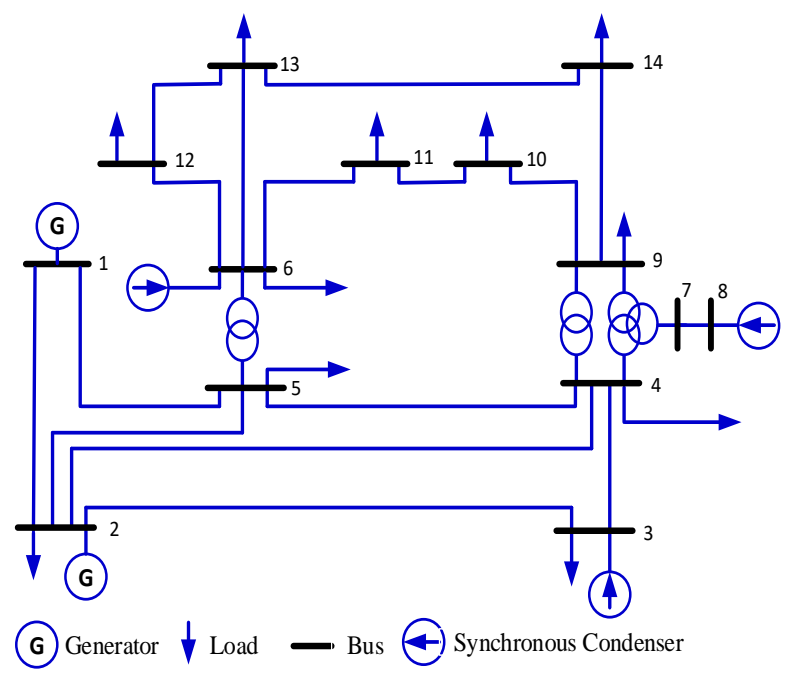

Figure. 1 The IEEE 14 bus system

Table 1. Bus voltages, indicators and powers at normal conditions

\begin{tabular}{|c|c|c|c|c|c|c|c|c|}
\hline $\begin{array}{l}\text { Bus } \\
\text { No. }\end{array}$ & $\mathbf{V}(\mathbf{p . u})$ & Bus Type & $\begin{array}{l}\text { Indicator } \\
\text { (L-index) }\end{array}$ & $\begin{array}{c}\mathbf{P}_{\mathbf{L}} \\
(\mathbf{M W})\end{array}$ & $\begin{array}{c}\mathbf{Q}_{\mathbf{L}} \\
\text { (MVAr) }\end{array}$ & $\begin{array}{c}\mathbf{P}_{\mathbf{G}} \\
(\mathbf{M W})\end{array}$ & $\begin{array}{c}\text { Qmax } \\
\text { (MVAr) }\end{array}$ & $\begin{array}{c}\text { Qmin } \\
\text { (MVAr) }\end{array}$ \\
\hline 1 & 1.060 & G & - & 0 & 0 & 232.4 & 100 & -100 \\
\hline 2 & 1.045 & $\mathrm{G}+\mathrm{L}$ & 0.06 & 21.7 & 12.7 & 40.0 & 80 & -40 \\
\hline 3 & 1.010 & $\mathrm{C}$ & - & 94.2 & 19.0 & 0.0 & 60 & 0.0 \\
\hline 4 & 1.019 & $\mathrm{~L}$ & 0.07 & 47.8 & -3.50 & 0.0 & - & - \\
\hline 5 & 1.020 & $\mathrm{~L}$ & 0.07 & 7.60 & 1.60 & 0.0 & - & - \\
\hline 6 & 1.070 & $\mathrm{C}$ & - & 11.2 & 7.50 & 0.0 & 40 & -6 \\
\hline 7 & 1.062 & 0 & - & 0.00 & 0.00 & 0.0 & - & - \\
\hline 8 & 1.090 & $\mathrm{C}$ & - & 0.00 & 0.00 & 0.0 & 24 & -6 \\
\hline 9 & 1.056 & $\mathrm{~L}$ & 0.04 & 29.5 & 16.6 & 0.0 & - & - \\
\hline 10 & 1.051 & $\mathrm{~L}$ & 0.05 & 9.00 & 5.80 & 0.0 & - & - \\
\hline 11 & 1.057 & $\mathrm{~L}$ & 0.04 & 3.50 & 1.80 & 0.0 & - & - \\
\hline 12 & 1.055 & $\mathrm{~L}$ & 0.04 & 6.10 & 1.60 & 0.0 & - & - \\
\hline 13 & 1.050 & $\mathrm{~L}$ & 0.05 & 13.5 & 5.80 & 0.0 & - & - \\
\hline 14 & 1.044 & $\mathrm{~L}$ & 0.06 & 14.9 & 5.00 & 0.0 & - & - \\
\hline
\end{tabular}




\subsection{The IEEE 14 bus system (test case study)}

The single line diagram of the IEEE 14 bus system shown in Fig. 1. Table 1 presents the results in normal conditions.

The line outage between buses 6 and 13 was selected in this work as an emergency test. Table 2 shows voltages and indicators after line outage. Five buses are critical, they are buses 9, 10, 12, 13 and 14, at which the bus voltage breaks down below the limit of stability $(0.9 \mathrm{pu})$, and they have the highest L-index.

From Table 2, the L-index value of load bus 13 and bus 14 are 0.5 and 0.75 , respectively, which are the highest values. On this basis, the candidate for load shedding is buses 13 and 14. For each iteration, the amount of load shedding is set at $10 \%$ of the loads on buses 13 and 14 .

In this case, the amount of shedding is rounded to $(15 \mathrm{X} 10 / 100=1.5 \mathrm{MW})$ for each iteration. The analysis is implemented to evaluate the impact of load shedding of 1.5MW from buses 13 and 14 .

Table 3 depicts the value of L-index for each bus at each iteration; the system voltage magnitude and L-index are re-evaluated. Following the first iteration, the system is still unstable; hence, the analysis is performed again to compute the L-index.

By this simulation, this procedure is repeated five times until the bus voltages of the system are stable (voltage magnitudes are above $0.9 \mathrm{pu}$ ), and the L-index is less than the threshold.

Table 3 and Table 4 show the obtained results of L-index calculation for each iteration and load shedding location and amount on the basis of highest L-index, respectively. Hence, the load shedding amount of 4.5MW from bus 13 and

Table 2. Bus voltages and indicators (L-index) after line outage between buses 6 and 13

\begin{tabular}{|c|c|c|}
\hline $\begin{array}{c}\text { Bus } \\
\text { No. }\end{array}$ & $\begin{array}{c}\mathbf{V} \\
\text { (p.u) }\end{array}$ & $\begin{array}{c}\text { Indicator } \\
(\text { L-index) }\end{array}$ \\
\hline 1 & 1.070 & - \\
\hline 2 & 1.051 & 0.05 \\
\hline 3 & 1.012 & - \\
\hline 4 & 1.020 & 0.07 \\
\hline 5 & 1.045 & 0.06 \\
\hline 6 & 1.071 & - \\
\hline 7 & 1.082 & - \\
\hline 8 & 1.010 & - \\
\hline 9 & 0.810 & 0.38 \\
\hline 10 & 0.800 & 0.40 \\
\hline 11 & 0.950 & 0.18 \\
\hline 12 & 0.810 & 0.38 \\
\hline 13 & 0.750 & 0.50 \\
\hline 14 & 0.650 & 0.75 \\
\hline
\end{tabular}

Table 3. Indicators (L-index) with iterations after line outage between buses 6 and 13 and load shedding from buses 13 and 14

\begin{tabular}{|c|c|c|c|c|c|}
\hline \multirow{2}{*}{$\begin{array}{c}\text { Bus } \\
\text { No. }\end{array}$} & \multicolumn{5}{|c|}{ Indicator (L-index) } \\
\cline { 2 - 6 } & $\mathbf{5}$ Iteration & $\mathbf{( 2 )}$ & $\mathbf{( 3 )}$ & $\mathbf{( 4 )}$ & $\mathbf{( 5 )}$ \\
\hline 2 & 0.05 & 0.05 & 0.05 & 0.05 & 0.06 \\
\hline 4 & 0.07 & 0.08 & 0.09 & 0.09 & 0.10 \\
\hline 5 & 0.06 & 0.07 & 0.07 & 0.08 & 0.09 \\
\hline 9 & 0.32 & 0.25 & 0.19 & 0.11 & 0.06 \\
\hline 10 & 0.33 & 0.26 & 0.20 & 0.13 & 0.07 \\
\hline 11 & 0.12 & 0.09 & 0.08 & 0.06 & 0.05 \\
\hline 12 & 0.33 & 0.26 & 0.18 & 0.12 & 0.06 \\
\hline 13 & 0.41 & 0.32 & 0.23 & 0.16 & 0.11 \\
\hline 14 & 0.61 & 0.47 & 0.34 & 0.22 & 0.11 \\
\hline
\end{tabular}

Table 4. Load shedding location and amount after line outage between buses 6 and 13

\begin{tabular}{|c|c|c|}
\hline Iteration & Location & Amount (MW) \\
\hline 1 & Bus 14 and 13 & $1.5+1.5$ \\
\hline 2 & Bus 14 and 13 & $1.5+1.5$ \\
\hline 3 & Bus 14 and 13 & $1.5+1.5$ \\
\hline 4 & Bus 14 & 1.5 \\
\hline 5 & Bus 14 & 1.5 \\
\hline
\end{tabular}

Table 5. Voltage profile and L-index improvement after line outage between buses 6 and 13 and after load shedding from buses 13 and 14

\begin{tabular}{|c|c|c|c|c|}
\hline \multirow[b]{2}{*}{$\begin{array}{l}\text { Bus } \\
\text { No. }\end{array}$} & \multicolumn{2}{|c|}{ Pre-Shedding } & \multicolumn{2}{|c|}{ Post-Shedding } \\
\hline & $\begin{array}{c}\text { V } \\
(\mathbf{p . u})\end{array}$ & $\begin{array}{l}\text { Indicator } \\
\text { (L-index) }\end{array}$ & $\begin{array}{c}\mathbf{V} \\
(\mathbf{p . u})\end{array}$ & $\begin{array}{l}\text { Indicator } \\
\text { (L-index) }\end{array}$ \\
\hline 1 & 1.070 & - & 1.060 & - \\
\hline 2 & 1.051 & 0.05 & 1.045 & 0.06 \\
\hline 3 & 1.012 & - & 1.010 & - \\
\hline 4 & 1.020 & 0.07 & 1.018 & 0.10 \\
\hline 5 & 1.045 & 0.06 & 1.038 & 0.09 \\
\hline 6 & 1.071 & - & 1.070 & - \\
\hline 7 & 1.082 & - & 1.079 & - \\
\hline 8 & 1.010 & - & 1.098 & - \\
\hline 9 & 0.810 & 0.38 & 1.046 & 0.06 \\
\hline 10 & 0.800 & 0.40 & 1.021 & 0.07 \\
\hline 11 & 0.950 & 0.18 & 1.051 & 0.05 \\
\hline 12 & 0.810 & 0.38 & 1.046 & 0.06 \\
\hline 13 & 0.750 & 0.50 & 1.000 & 0.11 \\
\hline 14 & 0.650 & 0.75 & 1.000 & 0.11 \\
\hline
\end{tabular}

7.5MW from bus 14.

The results of bus voltages enhancement after load shedding amount of $12 \mathrm{MW}$ from bus 14 and bus 13 are shown in Table 5 . These results prove that the voltages and L-index at all buses have clearly improved and that the system stability has recovered.

By using Eq. (23) and Eq. (24) was determined the percentage of voltage recovery of the network, 
which is $11.1 \%$. To ensure the reliability of the proposed approach, obtained results for voltage recovery of the network are compared with those of other approaches developed in the [8] as shown in Table 6; it is found that the results of the proposed solution are very closed to them.

Table 6. Comparison of proposed approach results with approaches developed in literature [8]

\begin{tabular}{|l|c|}
\hline \multicolumn{1}{|c|}{ Approach } & $\begin{array}{c}\text { Voltage } \\
\text { recovery \% }\end{array}$ \\
\hline Proposed approach & 11.10 \\
\hline Differential Evolution (DE) & 11.15 \\
\hline Particle Swarm Optimization (PSO) & 11.25 \\
\hline $\begin{array}{l}\text { Co-ordinated Aggregation based PSO } \\
\text { (CAPSO) }\end{array}$ & 11.19 \\
\hline Genetic Algorithm (GA) & 11.29 \\
\hline
\end{tabular}

\subsection{The Iraqi National Power Grid (case study)}

Fig. 2 shows a configuration of INPG $(400 \mathrm{kV})$. This grid consists of 27 buses; 13 buses are generation buses, and 14 buses are load buses and have 43 transmission lines. The lines represented by the nominal $\pi$ sections and the loads by a static admittance.

All data in the network are expressed in per-unit, referring to a common base power of 100MVA and the common base voltage of $400 \mathrm{kV}$. In the load flow solution, the slack bus for power grid was selected (bus No.1) which is Baiji Power station (BAJP). The input data for the INPG $(400 \mathrm{kV})$ according to the summer season (maximum load) on the $30^{\text {th }}$ of July 2018 [17].

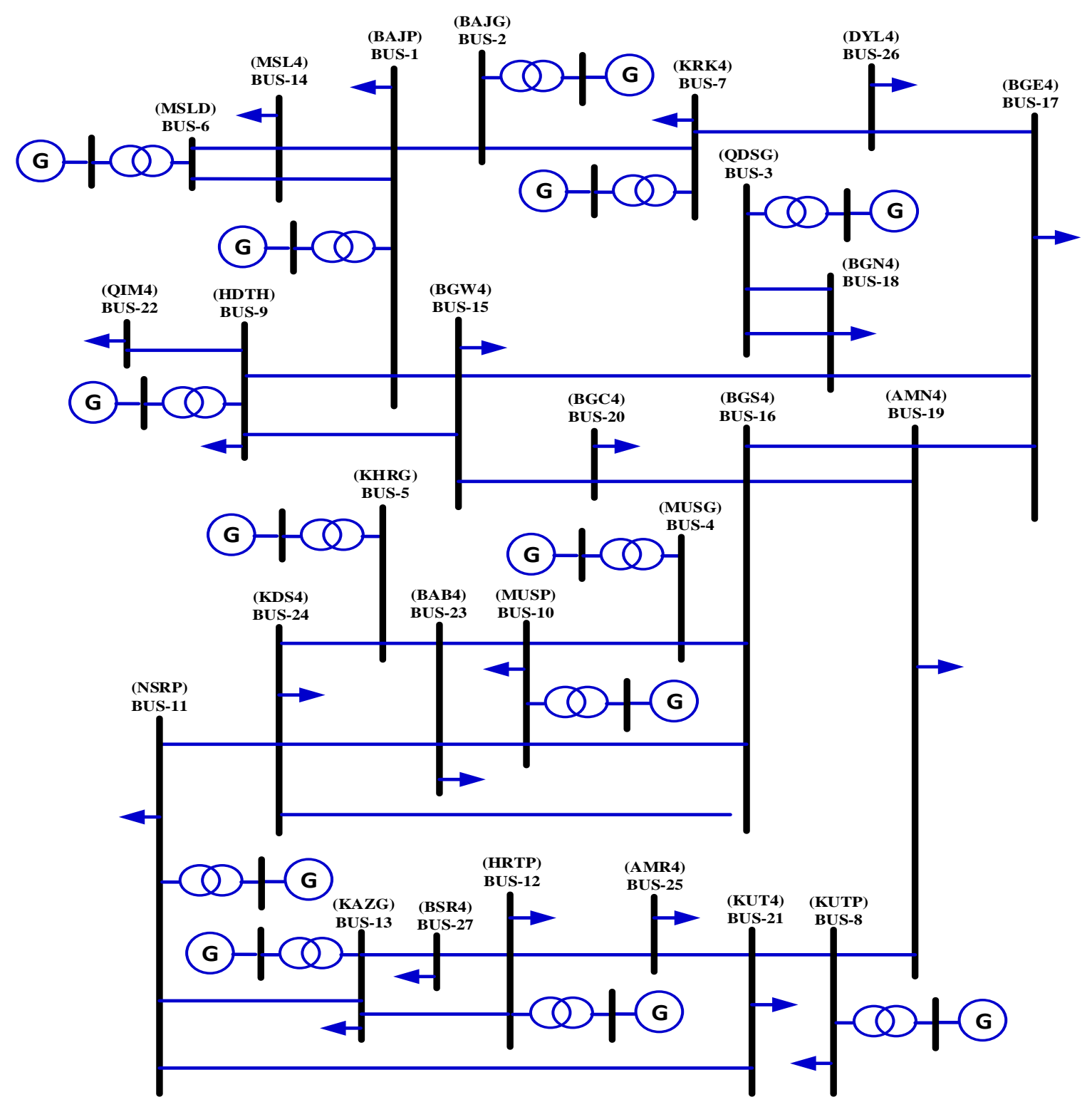

Figure.2 INPG $(400 \mathrm{kV})$, (With permission of the Iraqi National Control Center) 
Table 7. Bus voltage magnitudes, indicators and powers for INPG $(400 \mathrm{kV})$ with normal condition

\begin{tabular}{|c|c|c|c|c|c|c|c|}
\hline Bus No. & Bus Name & Bus Type & Voltage (p.u) & Indicator(L-index) & $\begin{array}{c}\mathbf{P}_{\mathbf{L}} \\
(\mathbf{M W})\end{array}$ & $\begin{array}{c}\mathbf{Q}_{\mathbf{L}} \\
\text { (MVAr) }\end{array}$ & $\begin{array}{c}\mathbf{P}_{\mathbf{G}} \\
(\mathbf{M W})\end{array}$ \\
\hline 1 & (BAJP) & $\mathrm{G}+\mathrm{L}$ & 0.9829 & 0.037 & 200.0 & 158.28 & 428.9 \\
\hline 2 & (BAJG) & $\mathrm{G}$ & 0.9825 & - & 0 & 0 & 300 \\
\hline 3 & (QDSG) & $\mathrm{G}$ & 0.9723 & - & 0 & 0 & 610 \\
\hline 4 & (MUSG) & $\mathrm{G}$ & 0.9716 & - & 0 & 0 & 245 \\
\hline 5 & (KHRG) & $\mathrm{G}$ & 0.9821 & - & 0 & 0 & 600 \\
\hline 6 & (MSLD) & $\mathrm{G}$ & 0.9747 & - & 0 & 0 & 400 \\
\hline 7 & (KRK4) & $\mathrm{G}+\mathrm{L}$ & 0.9654 & 0.092 & 200.0 & 189.00 & 220 \\
\hline 8 & (KUTP) & $\mathrm{G}+\mathrm{L}$ & 0.9838 & 0.035 & 180.0 & 70.380 & 660 \\
\hline 9 & (HDTH) & $\mathrm{G}+\mathrm{L}$ & 0.9725 & 0.073 & 140.0 & 74.010 & 145 \\
\hline 10 & (MUSP) & $\mathrm{G}+\mathrm{L}$ & 0.9716 & 0.078 & 134.0 & 161.02 & 420 \\
\hline 11 & (NSRP) & $\mathrm{G}+\mathrm{L}$ & 0.9543 & 0.112 & 370.0 & 158.00 & 480 \\
\hline 12 & (HRTP) & $\mathrm{G}+\mathrm{L}$ & 0.9770 & 0.049 & 100.0 & 94.000 & 300 \\
\hline 13 & (KAZG) & $\mathrm{G}+\mathrm{L}$ & 0.9791 & 0.041 & 104.1 & 139.00 & 220 \\
\hline 14 & (MSL4) & $\mathrm{L}$ & 0.9748 & 0.061 & 630.0 & 365.16 & 0 \\
\hline 15 & (BGW4) & $\mathrm{L}$ & 0.9640 & 0.098 & 690.0 & 360.91 & 0 \\
\hline 16 & (BGS4) & $\mathrm{L}$ & 0.9722 & 0.074 & 145.0 & 66.810 & 0 \\
\hline 17 & (BGE4) & $\mathrm{L}$ & 0.9742 & 0.065 & 4.200 & 72.930 & 0 \\
\hline 18 & (BGN4) & $\mathrm{L}$ & 0.9710 & 0.080 & 550.2 & 264.69 & 0 \\
\hline 19 & (AMN4) & $\mathrm{L}$ & 0.9740 & 0.066 & 180.0 & 100.20 & 0 \\
\hline 20 & (BGC4) & $\mathrm{L}$ & 0.9658 & 0.090 & 220.0 & 103.48 & 0 \\
\hline 21 & (KUT4) & $\mathrm{L}$ & 0.9817 & 0.039 & 165.4 & 105.91 & 0 \\
\hline 22 & (QIM4) & $\mathrm{L}$ & 0.9642 & 0.096 & 96.0 & 55.080 & 0 \\
\hline 23 & (BAB4) & $\mathrm{L}$ & 0.9745 & 0.063 & 116.0 & 82.860 & 0 \\
\hline 24 & (KDS4) & $\mathrm{L}$ & 0.9645 & 0.094 & 250.4 & 243.46 & 0 \\
\hline 25 & (AMR4) & $\mathrm{L}$ & 0.9997 & 0.020 & 19.00 & 98.940 & 0 \\
\hline 26 & (DYL4) & $\mathrm{L}$ & 0.9791 & 0.041 & 210.0 & 85.380 & 0 \\
\hline 27 & (BSR4) & $\mathrm{L}$ & 0.9766 & 0.052 & 304.5 & 113.00 & 0 \\
\hline
\end{tabular}

The proposed model and algorithm have been tested on the INPG $(400 \mathrm{kV})$. Table 7 illustrates the results for INPG $(400 \mathrm{kV})$ under normal conditions. As shown in Table 7, bus 11 has the highest value of L-index, which indicates that it is the weakest load bus in the grid. The emergency analysis is performed by selecting the critical line outage.

Five line-outage were tested, the results have shown that only four buses are critical buses at which the bus voltage drops below the limit of stability $(0.9 \mathrm{pu})$ and they have the highest L-index. They are buses 11, 12, 13 and 27 shown in Table 8 and also the results have shown the buses 12 and 27 are affected more by line outage.

In this work, the line outage is chosen between bus 13 (KAZG) and bus 27 (BSR4). Table 9 presents the results of bus voltage magnitudes and indicators for INPG $(400 \mathrm{kV})$ with the line outage between bus 13 and bus 27. From Table 9, the Lindex value of load bus 12 (HRTP) and bus 27 (BSR4) are 0.282 and 0.300 , respectively, which are the highest values. Accordingly, loads of buses 12 and 27 have to be shed.

Table 8. Bus voltage magnitudes and indicators according to tripping lines for INPG (400kV)

\begin{tabular}{|c|c|c|c|c|c|c|c|c|c|}
\hline \multicolumn{2}{|c|}{ Line outage } & \multicolumn{2}{c|}{ Bus 11 } & \multicolumn{2}{c|}{ Bus 12 } & \multicolumn{2}{c|}{ Bus 13 } & \multicolumn{2}{c|}{ Bus 27 } \\
\hline $\begin{array}{c}\text { From } \\
\text { Bus }\end{array}$ & $\begin{array}{c}\text { To } \\
\text { Bus }\end{array}$ & $\begin{array}{c}\text { V } \\
(\mathbf{p . u})\end{array}$ & $\begin{array}{c}\mathbf{L} \\
\text { (index) }\end{array}$ & $\begin{array}{c}\mathbf{V} \\
(\mathbf{p . u})\end{array}$ & $\begin{array}{c}\mathbf{L} \\
\text { (index) }\end{array}$ & $\begin{array}{c}\mathbf{V} \\
(\mathbf{p . u})\end{array}$ & $\begin{array}{c}\mathbf{L} \\
\text { (index) }\end{array}$ & $\begin{array}{c}\text { V } \\
\text { (p.u) }\end{array}$ & $\begin{array}{c}\mathbf{L} \\
\text { (index) }\end{array}$ \\
\hline 12 & 13 & 0.893 & 0.222 & 0.858 & 0.280 & 0.858 & 0.280 & 0.857 & 0.281 \\
\hline 5 & 24 & 0.885 & 0.238 & 0.857 & 0.281 & 0.858 & 0.280 & 0.855 & 0.282 \\
\hline 23 & 24 & 0.890 & 0.230 & 0.865 & 0.271 & 0.868 & 0.265 & 0.863 & 0.274 \\
\hline 19 & 8 & 0.898 & 0.210 & 0.858 & 0.280 & 0.860 & 0.276 & 0.855 & 0.282 \\
\hline 13 & 27 & 0.895 & 0.216 & 0.855 & 0.282 & 0.863 & 0.274 & 0.850 & 0.300 \\
\hline
\end{tabular}


Table 9. Bus voltage magnitudes, indicators for INPG $(400 \mathrm{kV})$ with the line outage between buses 13 and 27

\begin{tabular}{|c|c|c|c|c|}
\hline $\begin{array}{l}\text { Bus } \\
\text { No. }\end{array}$ & $\begin{array}{c}\text { Bus } \\
\text { Name }\end{array}$ & $\begin{array}{c}\text { Bus } \\
\text { Type }\end{array}$ & $\begin{array}{c}\text { Voltage } \\
\text { (p.u) }\end{array}$ & $\begin{array}{l}\text { Indicator } \\
\text { (L-index) }\end{array}$ \\
\hline 1 & (BAJP) & $\mathrm{G}+\mathrm{L}$ & 0.9829 & 0.037 \\
\hline 2 & (BAJG) & $\mathrm{G}$ & 0.9825 & - \\
\hline 3 & (QDSG) & $\mathrm{G}$ & 0.9723 & - \\
\hline 4 & (MUSG) & $\mathrm{G}$ & 0.9716 & - \\
\hline 5 & (KHRG) & $\mathrm{G}$ & 0.9821 & - \\
\hline 6 & (MSLD) & $\mathrm{G}$ & 0.9747 & - \\
\hline 7 & (KRK4) & $\mathrm{G}+\mathrm{L}$ & 0.9620 & 0.099 \\
\hline 8 & (KUTP) & $\mathrm{G}+\mathrm{L}$ & 0.9838 & 0.035 \\
\hline 9 & (HDTH) & $\mathrm{G}+\mathrm{L}$ & 0.9725 & 0.073 \\
\hline 10 & (MUSP) & $\mathrm{G}+\mathrm{L}$ & 0.9716 & 0.078 \\
\hline 11 & (NSRP) & $\mathrm{G}+\mathrm{L}$ & 0.8950 & 0.216 \\
\hline 12 & (HRTP) & $\mathrm{G}+\mathrm{L}$ & 0.8550 & 0.282 \\
\hline 13 & (KAZG) & $\mathrm{G}+\mathrm{L}$ & 0.8630 & 0.274 \\
\hline 14 & (MSL4) & $\mathrm{L}$ & 0.9748 & 0.061 \\
\hline 15 & (BGW4) & $\mathrm{L}$ & 0.9610 & 0.099 \\
\hline 16 & (BGS4) & $\mathrm{L}$ & 0.9722 & 0.074 \\
\hline 17 & (BGE4) & $\mathrm{L}$ & 0.9742 & 0.065 \\
\hline 18 & (BGN4) & $\mathrm{L}$ & 0.9720 & 0.078 \\
\hline 19 & (AMN4) & $\mathrm{L}$ & 0.9750 & 0.061 \\
\hline 20 & (BGC4) & $\mathrm{L}$ & 0.9628 & 0.098 \\
\hline 21 & (KUT4) & $\mathrm{L}$ & 0.9450 & 0.130 \\
\hline 22 & (QIM4) & $\mathrm{L}$ & 0.9622 & 0.099 \\
\hline 23 & (BAB4) & $\mathrm{L}$ & 0.9745 & 0.063 \\
\hline 24 & (KDS4) & $\mathrm{L}$ & 0.9525 & 0.116 \\
\hline 25 & (AMR4) & $\mathrm{L}$ & 0.9050 & 0.195 \\
\hline 26 & (DYL4) & $\mathrm{L}$ & 0.9775 & 0.048 \\
\hline 27 & (BSR4) & $\mathrm{L}$ & 0.850 & 0.300 \\
\hline
\end{tabular}

For each iteration, the amount of load shedding is set at $10 \%$ of the loads on buses 12 and 27 , at which the bus voltage drops below the limit of stability (0.9pu) and highest L-index. In this case, the amount of shedding for each step is rounded to $10 \mathrm{MW}$ at bus 12 and $30 \mathrm{MW}$ at bus 27 .

The analysis is implemented to evaluate the impact of load shedding at buses 12 and 27. The results of L-index calculation for each iteration, load shedding location and amount on the basis of highest L-index are illustrated in Tables 10 and 11. Accordingly, the load shedding amount of $30 \mathrm{MW}$ at bus 12 and $120 \mathrm{MW}$ at bus 27 .

The results of bus voltage enhancement after load shedding amount of 150MW from buses 12 and 27 are shown in Table 12. These go to prove that the voltages and L-index at all buses have improved significantly. Also, the voltage stability of the system has recovered. By using Eq. (23) and Eq. (24) can determine the percentage of voltage recovery of the network, which is $2.03 \%$.
Table 10. Indicators (L-index) with iterations after line outage between buses 13 and 27 and load shedding from buses 12 and 27 for INPG (400kV)

\begin{tabular}{|c|c|c|c|c|}
\hline \multirow{2}{*}{$\begin{array}{c}\text { Bus } \\
\text { No. }\end{array}$} & \multicolumn{4}{|c|}{ Indicator (L-index) } \\
\cline { 2 - 5 } & $\mathbf{4}$ & $\mathbf{( 2 )}$ & $\mathbf{( 3 )}$ & $\mathbf{( 4 )}$ \\
\hline 1 & 0.037 & 0.037 & 0.037 & 0.037 \\
\hline 7 & 0.096 & 0.096 & 0.095 & 0.093 \\
\hline 8 & 0.035 & 0.035 & 0.035 & 0.035 \\
\hline 9 & 0.073 & 0.073 & 0.073 & 0.073 \\
\hline 10 & 0.078 & 0.078 & 0.078 & 0.078 \\
\hline 11 & 0.196 & 0.150 & 0.132 & 0.112 \\
\hline 12 & 0.251 & 0.198 & 0.135 & 0.052 \\
\hline 13 & 0.225 & 0.186 & 0.126 & 0.045 \\
\hline 14 & 0.061 & 0.061 & 0.061 & 0.061 \\
\hline 15 & 0.098 & 0.098 & 0.098 & 0.098 \\
\hline 16 & 0.074 & 0.074 & 0.074 & 0.074 \\
\hline 17 & 0.065 & 0.065 & 0.065 & 0.065 \\
\hline 18 & 0.079 & 0.079 & 0.080 & 0.080 \\
\hline 19 & 0.061 & 0.062 & 0.063 & 0.064 \\
\hline 20 & 0.096 & 0.096 & 0.094 & 0.092 \\
\hline 21 & 0.123 & 0.092 & 0.061 & 0.041 \\
\hline 22 & 0.098 & 0.098 & 0.97 & 0.097 \\
\hline 23 & 0.063 & 0.063 & 0.063 & 0.063 \\
\hline 24 & 0.112 & 0.101 & 0.099 & 0.098 \\
\hline 25 & 0.191 & 0.120 & 0.095 & 0.073 \\
\hline 26 & 0.046 & 0.045 & 0.044 & 0.043 \\
\hline 27 & 0.280 & 0.235 & 0.195 & 0.112 \\
\hline & & & & \\
\hline
\end{tabular}

Table 11. Load shedding location and amount after line outage between buses 13and 27INPG (400kV)

\begin{tabular}{|c|c|c|}
\hline Iteration & Location & Amount (MW) \\
\hline 1 & Bus 12 and 27 & $10+30$ \\
\hline 2 & Bus 12 and 27 & $10+30$ \\
\hline 3 & Bus 12 and 27 & $10+30$ \\
\hline 4 & Bus 27 & 30 \\
\hline
\end{tabular}

\section{Conclusion}

In this work, the method of specifying the location and the amount of load shedding required and acceptable to alleviate voltage instability has been analyzed via a single execution of the proposed algorithm. The proposed approach is based on a linear relationship between bus power demands and the L-indicator of the threat of voltage instability.

The validation of the usefulness of the proposed method, the simulation was initially carried out on the test system IEEE 14 bus, when the line outage between buses 6 and 13, and after load shedding amount of $12 \mathrm{MW}$ from bus 14 and bus 13, the percentage of voltage recovery for the network was $11.1 \%$. The test results were compared with the results of a standard model and found it close. 
Table 12. Voltage profile and L-index improvement after line outage between buses 13 and 27 before and after load shedding from buses 12 and 27 for INPG (400kV)

\begin{tabular}{|c|c|c|c|c|c|c|}
\hline \multirow{2}{*}{$\begin{array}{l}\text { Bus } \\
\text { No. }\end{array}$} & \multirow{2}{*}{$\begin{array}{l}\text { Bus } \\
\text { Name }\end{array}$} & \multirow{2}{*}{$\begin{array}{l}\text { Bus } \\
\text { Type }\end{array}$} & \multicolumn{2}{|c|}{ Pre-Shedding } & \multicolumn{2}{|c|}{ Post-Shedding } \\
\hline & & & $\begin{array}{c}\text { Voltage } \\
\text { (p.u) }\end{array}$ & $\begin{array}{l}\text { Indicator } \\
\text { (L-index) }\end{array}$ & $\begin{array}{l}\text { Voltage } \\
\text { (p.u) }\end{array}$ & $\begin{array}{l}\text { Indicator } \\
\text { (L-index) }\end{array}$ \\
\hline 1 & (BAJP) & $\mathrm{G}+\mathrm{L}$ & 0.9829 & 0.037 & 0.9829 & 0.037 \\
\hline 2 & (BAJG) & G & 0.9825 & - & 0.9825 & - \\
\hline 3 & (QDSG) & G & 0.9723 & - & 0.9723 & - \\
\hline 4 & (MUSG) & G & 0.9716 & - & 0.9716 & - \\
\hline 5 & (KHRG) & $\mathrm{G}$ & 0.9821 & - & 0.9821 & - \\
\hline 6 & (MSLD) & $\mathrm{G}$ & 0.9747 & - & 0.9747 & - \\
\hline 7 & (KRK4) & $\mathrm{G}+\mathrm{L}$ & 0.9620 & 0.099 & 0.9650 & 0.093 \\
\hline 8 & (KUTP) & $\mathrm{G}+\mathrm{L}$ & 0.9838 & 0.035 & 0.9838 & 0.035 \\
\hline 9 & (HDTH) & $\mathrm{G}+\mathrm{L}$ & 0.9725 & 0.073 & 0.9725 & 0.073 \\
\hline 10 & (MUSP) & $\mathrm{G}+\mathrm{L}$ & 0.9716 & 0.078 & 0.9716 & 0.078 \\
\hline 11 & (NSRP) & $\mathrm{G}+\mathrm{L}$ & 0.895 & 0.216 & 0.9543 & 0.112 \\
\hline 12 & (HRTP) & $\mathrm{G}+\mathrm{L}$ & 0.855 & 0.282 & 0.9766 & 0.052 \\
\hline 13 & (KAZG) & $\mathrm{G}+\mathrm{L}$ & 0.863 & 0.274 & 0.9780 & 0.045 \\
\hline 14 & (MSL4) & $\mathrm{L}$ & 0.9748 & 0.061 & 0.9748 & 0.061 \\
\hline 15 & (BGW4) & $\mathrm{L}$ & 0.9610 & 0.099 & 0.9640 & 0.098 \\
\hline 16 & (BGS4) & $\mathrm{L}$ & 0.9722 & 0.074 & 0.9722 & 0.074 \\
\hline 17 & (BGE4) & $\mathrm{L}$ & 0.9742 & 0.065 & 0.9742 & 0.065 \\
\hline 18 & (BGN4) & $\mathrm{L}$ & 0.9720 & 0.078 & 0.9710 & 0.080 \\
\hline 19 & (AMN4) & $\mathrm{L}$ & 0.9750 & 0.061 & 0.9742 & 0.064 \\
\hline 20 & (BGC4) & $\mathrm{L}$ & 0.9628 & 0.098 & 0.9654 & 0.092 \\
\hline 21 & (KUT4) & $\mathrm{L}$ & 0.9450 & 0.130 & 0.9791 & 0.041 \\
\hline 22 & (QIM4) & $\mathrm{L}$ & 0.9622 & 0.099 & 0.9641 & 0.097 \\
\hline 23 & (BAB4) & $\mathrm{L}$ & 0.9745 & 0.063 & 0.9745 & 0.063 \\
\hline 24 & (KDS4) & $\mathrm{L}$ & 0.9525 & 0.116 & 0.9640 & 0.098 \\
\hline 25 & (AMR4) & $\mathrm{L}$ & 0.9050 & 0.195 & 0.9725 & 0.073 \\
\hline 26 & (DYL4) & $\mathrm{L}$ & 0.9775 & 0.048 & 0.9785 & 0.043 \\
\hline 27 & (BSR4) & $\mathrm{L}$ & 0.850 & 0.300 & 0.9543 & 0.112 \\
\hline
\end{tabular}

After that, for the application of the proposed method, the simulation was performed for the Iraqi National Power Grid $(400 \mathrm{kV})$ with many emergencies, such as lines outage has been considered in order to find out location and amount of the load to be shed at each bus of grid as a precaution to avoid voltage instability. When the line outage between buses 13 and 27, and after load shedding amount of 150MW from buses 12 and 27, the percentage of voltage recovery for the network was $2.03 \%$. Results proved that the use of load shedding technology has improved voltage stability and saved the network from collapse. A vital feature emerges that the proposed model and algorithm are suitable for power system operation and planning purposes. In future research, we plan to implement the UFLS strategy to avoid an imbalance between available generation and demand in the Iraqi National P National Power Grid.

\section{References}

[1] H. Bai and V. Ajjarapu, "A novel online load shedding strategy for mitigating fault-induced delayed voltage recovery", IEEE Transactions on Power Systems, Vol.26, No.1, pp.294-304, 2010.

[2] P. Kundur, J. Paserba, V. Ajjarapu, G. Andersson, A. Bose, C. Canizares, N. Hatziargyriou, D. Hill, A. Stankovic, C. Taylor, and T. Cutsem, "Definition and classification of power system stability", IEEE Transactions on Power Systems, Vol.19, pp.1387-1401, 2004.

[3] A. Ghaleh, M. Sanaye-Pasand, and A. Saffarian, "Power system stability enhancement using a new combinational load-shedding algorithm", IET Generation, Transmission \& Distribution, Vol.5, pp.551-560, 2011.

[4] A. Saffarian and M. Sanaye-Pasand, "Enhancement of power system stability using adaptive combinational load shedding 
methods", IEEE Transactions on Power Systems, Vol.26, pp.1010-1020, 2010.

[5] A. Wiszniewski, "New criteria of voltage stability margin for the purpose of load shedding", IEEE Transactions on Power Delivery, Vol.22, No.3, pp.1367-1371, 2007.

[6] A. Girgis and S. Mathure, "Application of active power sensitivity to frequency and voltage variations on load shedding", Electric Power Systems Research, Vol.80, No.3, pp.306-310, 2010.

[7] $\mathrm{X} . \mathrm{Fu}$ and $\mathrm{X}$. Wang, "Determination of load shedding to provide voltage stability", International Journal of Electrical Power \& Energy Systems, Vol.33, No.3, pp.515-521, 2011.

[8] L. Arya, P. Singh, and L. Titare, "Optimum load shedding based on sensitivity to enhance static voltage stability using DE", Swarm and Evolutionary Computation, Vol.6, pp.25-38, 2012.

[9] M. Klaric, I. Kuzle, and S. Tesnjak, "Example of undervoltage load shedding implementation", in AFRICON, pp.1-6, 2007.

[10] S. Ladhani and W. Rosehart, "Under voltage load shedding for voltage stability overview of concepts and principles", In: Proc. of IEEE Power Engineering Society General Meeting, pp.1597-1602, 2004.

[11] C. Affonso, L. da Silva, F. Lima, and S. Soares, "MW and MVar management on supply and demand side for meeting voltage stability margin criteria", IEEE Transactions on Power Systems, Vol.19, pp.1538-1545, 2004.

[12] F. Althowibi and M. Mustafa, "Voltage stability calculations in power transmission lines: Indications and allocations", In: Proc. of IEEE International Conference on Power and Energy, pp.390-395, 2010.

[13] P. Kessel and H. Glavitsch, "Estimating the voltage stability of a power system", IEEE Transactions on Power Delivery, Vol.1, pp.346-354, 1986.

[14] H. Bevrani, A. Tikdari, and T. Hiyama, "Power system load shedding: Key issues and new perspectives", World Academy of Science, Engineering and Technology, Vol.65, pp.199204, 2010.

[15] D. Nataraj, R. Loganathan, M. Veerasamy, and V. Jawalkar, "Optimizing Radial Distribution System for Minimizing Loss Reduction and Voltage Deviation Indices Using Modified Grey Wolf's Algorithm", International Journal of Intelligent Engineering and Systems, Vol.11, No.6, pp.177-189, 2018.
[16] J. Nick, A. Ron, C. Peter, K. Daniel, and S. Goran, "Embedded Generation", IEE Power and Energy, Series 31, 2000.

[17] Iraqi National Control Center (INCC), Iraqi Ministry of Electricity, (Accessed on 30th of July 2018). 